\title{
IMAGERI: KESAN TERHADAP PRESTASI CONVERSION KICK DALAM SUKAN RAGBI
}

\author{
Mohd Huzairi Mohd Sani ${ }^{1,2} \&$ Thariq Khan Azizuddin Khan ${ }^{2}$ \\ ${ }^{1}$ Kementerian Pendidikan Malaysia, Malaysia \\ ${ }^{2}$ Fakulti Sains Sukan dan Kejurulatihan, Universiti Pendidikan Sultan Idris, Tg Malim, Perak, \\ Malaysia \\ Email: huzairisani@yahoo.com
}

\begin{abstract}
Abstrak
Jurnal Sains Sukan dan Pendidikan Jasmani 7(1): Received: 30 January 2018, Accepted: 1 March 2018 - Kajian ini adalah bagi melihat kesan program latihan psikologi iaitu latihan imageri terhadap prestasi dalam sukan ragbi. Ia menilai kesan latihan fizikal dan imageri audio terhadap prestasi conversion kick selama empat minggu dengan kekerapan intervensi tiga sesi seminggu. Peserta yang terlibat terdiri daripada tiga puluh orang ahli dari kelab ragbi sekolah. Soal selidik Sport Imagery Ability Measure (SIAM) yang telah dialih ke dalam Bahasa Malaysia digunakan sebagai saringan bagi melihat kebolehan imageri peserta. Penyelidikan dijalankan dengan membina intervensi pada imageri audio yang dijalankan bersama latihan fizikal berasaskan kepada Imagery Training Program (ITP). Kaedah eksperimen yang digunakan adalah melibatkan satu kumpulan kawalan dan satu kumpulan rawatan yang melalui proses ujian pra, intervensi dan ujian pasca. Hasil kajian mendapati tidak terdapat perbezaan yang signifikan di antara kedua-dua kumpulan yang terlibat. Perbincangan, limitasi dan kajian akan datang akan dibincangkan pada bahagian yang terakhir.
\end{abstract}

Kata kunci: Imageri, Sukan, ragbi, Conversion kick, Imagery Training Program (ITP). 


\title{
IMAGERY: EFFECTS ON CONVERSION KICK PERFORMANCE IN RUGBY
}

\begin{abstract}
This study is to look at the impact of imagery training programs on performance in rugby. The study assessed the impact of physical training and audio imagery on conversion kick performance over four weeks with intervening frequency of three sessions per week. Participants involved consisted of thirty members from a school rugby club. The Sport Imagery Ability Measure (SIAM) questionnaire which has been converted into Bahasa Malaysia is used as a screen to measure participant's imagery abilities. This research is been conducted by developing interventions on audio imagery conducted with physical training based on the Imagery Training Program (ITP). The experimental method used involves a control group and a group of treatment that underwent pre-test, intervention and post-test. The findings showed no significant different between the two groups involved. Discussions, limitations and future studies were discussed in the last section.
\end{abstract}

Keywords: imagery, sport, rugby, conversion kick, imagery training program (ITP) 


\section{PENGENALAN}

Ragbi adalah sukan kompetitif yang memerlukan tahap prestasi yang terbaik bagi menjamin kemenangan pasukan. Salah satu kemahiran penting yang diperlukan adalah kemahiran melakukan conversion kick. International Rugby Board (IRB, 2013) menjelaskan conversion kick adalah aspek berguna dalam pungutan mata bagi permainan ragbi untuk menentukan keputusan perlawanan. Terdapat pelbagai cara yang digunakan bagi meningkatkan prestasi conversion kick atlet ragbi. Kaedah yang sering diguna pakai untuk meningkatkan prestasi dalam sukan adalah kaedah latih tubi kemahiran (Kossert \& Munroe-Chandler, 2007). Selain latih tubi kemahiran, Pavely et al, (2009) menjelaskan dalam sukan ragbi perlunya penekanan diberikan terhadap aspek psikologi bagi membolehkan atlet meningkatkan prestasi secara menyeluruh dan mengurangkan risiko kecederaan. Latihan psikologi ini adalah penting bukan sahaja menyediakan prestasi terbaik atlet malah turut membantu meningkatkan self-efficacy, tumpuan dan motivasi atlet (William \& Cumming, 2011; Malouff et al., 2008). Oleh itu Morris et al. (2005) menjelaskan bahawa latihan psikologi seperti imageri dan modeling adalah bersesuaian untuk digunakan dalam pelbagai jenis sukan sebagai sokongan kepada latihan fizikal bagi tujuan mempercepatkan proses peningkatan prestasi. Post et al. (2012) pula membuat cadangan supaya latihan kemahiran psikologi dijalankan sama seperti amalan latihan fizikal bagi memperoleh kesan yang optimum.

Imageri menurut Morris et al. (2005) adalah proses membina semula pengalaman lama atau baru sama seperti keadaan sebenar sementara itu Roberts et al. (2008) mendefinisikan imageri sebagai penggunaan pelbagai deria bagi mencipta semula pengalaman dalam minda. Burton dan Redeke (2008) dan Smith et al. (2007) menjelaskan bahawa imageri adalah satu proses kognitif yang didapati dapat meningkatkan pembelajaran dan prestasi terhadap kemahiran motor. Ciri-ciri multi sensori (visual, kinesthetic, audiotory, gustatory dan tactile) yang tersirat di dalam gambaran imej akan hadir semasa melaksanakan latihan mental ini. Proses visual memerlukan penglibatan semua organ deria kita di samping peristiwa-peristiwa yang dibayangkan cukup jelas dalam bentuk rangsangan fikiran dalam otak yang sangat dekat dengan realiti (Reiser et al., 2011). Oleh itu, atlet boleh mendapat manfaat daripada latihan imageri untuk mengukuhkan, membuat perincian, meneroka, mengingat kemahiran sukan baru atau lama dan juga untuk tujuan spesifik antaranya seperti strategi, taktik dan teknik sukan dan pemulihan sukan (Mouratidis et al., 2008).

Kerangka teori bio-information oleh Lang $(1979,1977)$ digunakan bagi menerangkan kesan imageri terhadap prestasi. Teori ini telah mendapat perhatian ramai pengkaji kerana intervensi yang berasaskan kepada teori ini telah menyumbang kepada peningkatan prestasi di dalam sukan (Callow et al., 2006; Post et al., 2010). Lang menjelaskan bahawa imageri adalah set cadangan atau perkara berfungsi secara tersusun yang disimpan di dalam memori jangka panjang. Modifikasi usul atau cadangan akan membawa kepada perubahan tingkah laku. Lang juga mengusulkan semua pengetahuan boleh dipersembahkan dalam memori sebagai unit informasi tentang sesuatu objek, hubungan dan acara yang dikenali sebagai propositions. Lang menambah, terdapat tiga kategori asas dalam mempersembahkan imageri yang dikenali sebagai 'stimulus propositions', 'respon proposition' dan 'meaning propositions'. Stimulus proposition adalah berkaitan persekitaran luar, respons proposition pula adalah aktiviti motor dan perubahan automatik. Apabila individu terlibat dengan imageri, mereka sebenarnya merangsang bahagian-bahagian stimulus (yang mengandungi kandungan imej) dan bahagianbahagian tindak balas ataupun respons yang berfungsi sebagai stimuli dalam situasi tersebut. Menurut Lang lagi pembelajaran dan prestasi adalah dua perkara yang saling berkaitan melalui imageri. Melalui pengulangan latihan prestasi imageri akan menjadikan individu terbabit dapat mengadaptasi keadaan stimulus dan respons yang terbaik. 
Kajian ini adalah untuk melihat kesan latihan psikologi iaitu latihan imageri yang dijalankan bersama latihan fizikal berbanding dengan kumpulan yang hanya menjalani latihan fizikal sahaja terhadap prestasi dalam sukan ragbi pada aspek kemahiran tertutup iaitu kemahiran conversion kick.

\section{Objektif Kajian}

Kajian ini dilakukan adalah untuk melihat kesan latihan imageri terhadap prestasi sukan ragbi. Secara spesifiknya, objektif kajian ini adalah untuk: 1) melihat kesan latihan fizikal sahaja terhadap prestasi conversion kick, (2) melihat kesan latihan imageri bersama latihan fizikal terhadap prestasi conversion kick.

\section{Kajian Lampau}

Dalam bidang psikologi gunaan, terdapat banyak kajian terdahulu yang memperlihatkan keberkesanan latihan imageri dengan prestasi sukan (e.g. Smith et al., 2007; Bell \& Thompson, 2007; Morris et al., 2005; Hall, 2001; Martin et al., 1999). Burton dan Raedeke, (2008) menjelaskan bahawa kebanyakan kajian lepas secara amnya membuktikan bahawa latihan imageri mempunyai faedah dalam meningkatkan prestasi sukan, begitu juga mengikut Short, Ross-Stewart, \& Monsma (2006), lebih daripada 200 kajian yang dijalankan menunjukkan penggunaan imageri memberi maklum balas yang sangat positif terhadap peningkatan prestasi.

Latihan imageri dan peningkatan prestasi sukan juga dilihat secara temu bual dan testimoni mereka yang telah berjaya dalam bidang masing-masing antaranya atlet profesional seperti Jack Nicklaus (golf), Greg Lougannis (diving) dan Chris Evert (tenis) (Morris et al., 2005). Aktiviti yang menunjukkan kaedah imageri telah berjaya dalam meningkatkan prestasi sukan adalah seperti sukan besbol, bola keranjang (Post et al., 2010; Rodlo, 2007), golf (Bell \& Thompson, 2007), ragbi (Evans, Jones, \& Mullen, 2004), bola sepak (Jordet, 2005), renang (Post, et al., 2012; Wade, Munroe-Chandler, \& Hall, 2007) dan bola tampar (Afrouzeh, Sohrabi, Torbati, Gorgin, \& Mallet, 2013).

Dalam mencapai hasrat untuk membina dan meningkatkan prestasi yang cemerlang, atlet seharusnya menggunakan imageri secara berterusan dan sistematik kerana peningkatan prestasi tidak berlaku secara mendadak (Malouff et al., 2008; Mamassis, \& Doganis, 2004; Martin et al., 1999). Kemahiran imageri perlu diberi perhatian memandangkan kebanyakan atlet melaporkan bahawa mereka menggunakan imageri dengan kerap sebelum pertandingan dijalankan ia membantu meningkatkan prestasi (Robin, Dominique, Toussaint, Blandin, \& LeHer, 2007). Walau bagaimanapun kesan ke atas prestasi secara keseluruhannya masih tidak jelas. Ada sesetengah kajian mendapati ia menunjukkan kesan positif dan ada yang melaporkan perkara sebaliknya (Gould, Damarjian, \& Greenleaf, 2002). Atlet biasanya menggunakan imageri positif sebagai sebahagian daripada rutin mereka bagi menambah baik prestasi dan beraksi pada tahap optimum (Cumming, Nordin, Horton \& Reynolds, 2006). Sementara itu, Short, Bruggeman, Engel, Marback, Wang, Willadsen, dan Short (2002) menambah, kajian terhadap pelajar pendidikan jasmani dan sains latihan di sebuah universiti telah diuji bagi mengesan imageri ubah suai dan self-efficacy terhadap kemahiran golf putting. Dapatan menunjukkan terdapat peningkatan prestasi bukan sahaja dalam penggunaan imageri ubah suai malahan meningkatkan self-efficacy dalam tugasan golf putting.

Robin et al. (2007) telah menjalankan ujian ke atas latihan imageri dan melihat kesannya terhadap peningkatan dalam ketepatan menghantar semula bola tenis mendapati terdapatnya peningkatan prestasi selepas intervensi imageri diperkenalkan sementara itu Bell dan Thompson (2007) juga mendapati perkara yang sama berlaku dalam sukan golf. Berbeza 
dengan dapatan sebelumnya, Gurupreet, Nishan dan Pankaj (2014) telah menguji intervensi imageri terhadap prestasi pemain bola sepak dalam kemahiran menghantar dan kawalan bola. Setelah menganalisis ujian menggunakan McDonald soccer skill, pelaporan dapatan pada Ttest dan chi square tidak menunjukkan perbezaan yang signifikan terhadap kumpulan intervensi. Begitu juga kajian 8 minggu yang dijalankan oleh Nasr Chalghaf, Sbaa, Leveque, Azaiez (2013) terhadap atlet judo juga mendapati tidak terdapat perbezaan yang signifikan terhadap peningkatan teknik perlakuan judo.

Satu penjelasan mengapa sesetengah kajian mendapati keputusan yang berbeza adalah kerana faktor perbezaan individu yang mempengaruhi pembelajaran, prestasi dan kognitif (Vealey \& Greenleaf, 2006). Penyelidik tidak dapat mengawal keupayaan imageri, kawalan dan pengalaman yang lepas yang ada pada atlet. Keupayaan imageri mempunyai dua faktor yang berpengaruh iaitu bagaimana kejelasan atlet boleh melihat imej dan bagaimana terperinci nya imej yang muncul kepada mereka dan faktor keupayaan atlet untuk memanipulasi aspek imej sebagaimana perubahan yang dikehendaki (Vealey \& Greenleaf, 2006).

\section{KAEDAH KAJIAN}

Kajian ini dijalankan dengan menggunakan kaedah eksperimental ujian pra, intervensi dan ujian pasca di mana terdapat satu kumpulan kawalan dan satu kumpulan rawatan. Kumpulan kawalan adalah kumpulan yang hanya melakukan latihan fizikal sahaja iaitu latihan conversion kick sementara itu kumpulan intervensi terdiri daripada kumpulan imageri. Kajian ini berlangsung selama empat minggu dengan kekerapan intervensi tiga kali seminggu.

\section{Peserta}

Tiga puluh peserta lelaki yang menyertai kelab ragbi Sekolah Menengah Sains Hulu Selangor yang berumur di antara 14 hingga 15 tahun akan dipilih untuk menjadi peserta secara sukarela dalam kajian ini. Mereka yang dipilih adalah mereka yang mempunyai asas ragbi selama satu tahun dan tidak pernah menjalani apa-apa latihan psikologi sebelum ini. Mereka juga tidak pernah mewakili sekolah dalam mana-mana kejohanan ragbi. Sebelum pengumpulan data dibuat, peserta akan dimaklumkan dahulu tujuan kajian yang akan dilakukan. Surat kebenaran ibu bapa juga akan diberikan kepada peserta untuk ditandatangani sebagai tanda persetujuan.

\section{Instrumen}

Soal selidik Sport Imagery Ability Measure (SIAM) oleh Watt dan Morris (1998) yang telah dialih bahasa ke dalam Bahasa Malaysia ini terbahagi kepada dua bahagian iaitu bahagian pertama mengandungi maklumat berkaitan dengan demografi subjek manakala bahagian kedua pula mengandungi empat aktiviti imageri yang mana setiap aktiviti mempunyai dua belas soalan. Peserta akan diminta untuk membuat imageri ke atas situasi yang telah diperdengarkan. Masa untuk berimageri adalah selama 60 saat. Kemudian peserta akan memberi respons terhadap dua belas item yang menjadi asas kepada lima dimensi imageri (kejelasan imej, kawalan imej, kelajuan imej, kemudahan dalam membina imej dan tempoh masa penjanaan imej). Ia juga melibatkan enam deria semasa melakukan imageri (visual, audio, kinestatik, rasa, bau dan sentuhan). 
Setiap peserta akan melakukan ujian conversion kick ubah suai yang dikeluarkan oleh Rugby Federation Union (RFU) yang dibina oleh Barrit, (2008). Kawasan tendangan adalah berada pada tiga posisi yang berbeza iaitu di tengah-tengah tiang gol dan dua tempat di sisi iaitu kiri dan kanan. Keluasan bagi sepakan conversion kick di sebelah kiri dan kanan adalah selebar lima meter dan jarak tendangan adalah lima belas meter di kawasan tengah dan dua puluh meter di kawasan sisi. Kekerapan intervensi ini adalah selama tiga kali seminggu selama empat minggu.

\section{Skrip dan Audio Imageri}

Skrip imageri bagi rawatan terhadap kemahiran conversion kick akan disediakan dalam bentuk tulisan dan kemudian dipindahkan ke dalam bentuk audio. Skrip imageri ini fokus kepada peningkatan dalam perlakuan atau kemahiran conversion kick. Kumpulan imageri audio akan mendapat intervensi ini. Setiap skrip adalah berasaskan kepada ITP dan bio-informational teori Lang's (1977, 1979). Setiap skrip akan mengandungi aspek stimulus dan tindak balas. Aspek stimulus menjelaskan situasi yang diimejkan seperti tiang gol manakala respons pula adalah tindakan daripada situasi tertentu. Selaras dengan model ITP yang dicadangkan oleh Morris et al. (2005) skrip juga merangkumi pelbagai deria seperti visual dan kinestatik, persekitaran seperti semasa latihan dan ketepatan perlakuan seperti kontak bola dengan kaki. Semua aspek ini digabungkan untuk meningkatkan kejelasan pada setiap peserta yang terlibat dalam kajian juga bagi memudahkan mereka melakukan imageri pada perlakuan yang betul dalam melakukan kemahiran conversion kick. Menurut William, Cooley, Newell, Weibull dan Cumming (2013) tiada istilah betul atau salah dalam merangka dan menjalankan skrip imageri, ia bersifat fleksibel dan boleh berubah-ubah mengikut kesesuaian atlet. Ia juga memerlukan maklum balas daripada atlet.

\section{Pengumpulan Data}

Video notational analisys digunakan untuk melihat perlakuan dan skor yang didapati oleh peserta. Data akan dikumpulkan daripada ujian pra dan ujian pasca. Selepas 4 minggu intervensi diberikan, ujian pasca pula dilakukan.

\section{Data Analisis}

Penyelidik mendapatkan data kuantitatif melalui skor yang diperoleh oleh setiap kumpulan dengan menggunakan borang skor conversion kick dan video notational analysis. Skor ujian pra akan dikumpulkan dan dicatatkan ke dalam borang skor individu dan dicampurkan bagi mendapatkan min kumpulan. Skor dinilai daripada empat percubaan pada setiap spot sepakan. Kesemua peserta harus melakukan dua belas iaitu tiga spot sepakan conversion kick yang ditetapkan. Mata akan dikira berpandukan kepada jumlah jaringan yang dapat dihasilkan oleh setiap individu dan dikumpulkan menjadi markah keseluruhan kumpulan. Skor maksimum yang akan diperoleh adalah 20 mata bagi setiap individu manakala skor minimum yang boleh diperoleh adalah 1. Bagi mengukur tahap perbezaan kumpulan dalam kemahiran conversion kick penyelidik menggunakan ujian t yang menggunakan skor min sebagai asas pengiraan. Min kumpulan akan dibuat perbandingan dalam ujian pra dan ujian pasca untuk menilai sama ada terdapat nilai yang signifikan atau pun tidak pada kumpulan. Aras signifikan yang ditetapkan adalah $\alpha=0.05$. 


\section{KEPUTUSAN}

30 peserta yang telah lulus ujian SIAM dijemput secara suka rela untuk menjadi peserta bagi kajian ini. Mereka yang menjadi peserta telah mencapai markah 60 daripada 160 dalam ujian SIAM. Ini dikira berdasarkan perkiraan yang sama digunakan oleh Watt dan Morris (1998).

Analisis ujian t sampel tidak bersandar digunakan bagi membandingkan skor min ujian conversion kick bagi setiap kumpulan. Bagi kumpulan kawalan iaitu kumpulan latihan fizikal percubaan conversion kick percubaan pasca menunjukkan skor min conversion kick adalah (M $=28.33, \mathrm{SD}=8.41)$ adalah tidak berbeza daripada skor min conversion kick percubaan pra $(\mathrm{M}$ $=28.00, \mathrm{SD}=10.35), \mathrm{t}(14)=-0.26, \mathrm{p}=.824$. Pencapaian adalah tidak signifikan.

Bagi kumpulan intervensi (latihan imageri), dapatan skor ujian pasca adalah $(\mathrm{M}=$ $30.13, \mathrm{SD}=9.89)$ berbanding dengan skor ujian pra iaitu $(\mathrm{M}=27.73, \mathrm{SD}=9.83), \mathrm{t}(14)=-$ $2.10, \mathrm{p}=.05$ menunjukkan dapatan kumpulan ini juga mempunyai nilai yang tidak signifikan tetapi terdapat peningkatan dalam min pencapaian keseluruhan kumpulan berbanding dengan min kumpulan latihan fizikal.

\section{PERBINCANGAN}

Dalam kajian ini tidak terdapat perbezaan yang signifikan terhadap dua kumpulan latihan fizikal dengan kumpulan intervensi imageri. Keputusan ini adalah selari dengan kajian yang dilakukan oleh Gurupreet, Nishan dan Pankaj (2014) yang juga menjelaskan tidak terdapat peningkatan terhadap atlet bola sepak yang dikaji olehnya. Bagi ahli kelab sukan ragbi sekolah, adalah sukar bagi mereka melakukan conversion kick apabila pendedahan terhadapnya adalah kurang. Bagi atlet latihan imageri perlu dilakukan secara berterusan untuk meningkatkan prestasi (Malouff, McGee, Halford, \& Rook, 2008; Mamassis, \& Doganis, 2004; Martin et al., 1999) oleh itu latihan imageri ini memerlukan masa terutama melibatkan ahli kelab sukan ragbi sekolah untuk menjadi lebih mahir. Dapatan kajian ini juga bersetuju dengan konsep bioinformation oleh Lang $(1979,1977)$ yang menjelaskan bahawa imageri adalah set cadangan atau perkara berfungsi secara tersusun yang disimpan di dalam memori jangka panjang. Modifikasi usul atau cadangan akan membawa kepada perubahan tingkah laku. Oleh itu perubahan min dapatan kumpulan imageri membenarkan konsep ini.

Walau bagaimanapun kajian ini mempunyai limitasi. Ia melihat dari aspek peningkatan prestasi menggunakan imageri audio terhadap sekumpulan ahli kelab ragbi sekolah. Peserta yang mungkin kurang pendedahan mengenai aspek imageri dan memerlukan masa untuk mengadaptasi ke dalam latihan mereka. Oleh itu kajian jangka panjang adalah diperlukan untuk melihat keberkesanan terhadap ahli-ahli kelab ragbi di sekolah-sekolah. Aspek kemahiran pula tidak terbatas terhadap kemahiran close skill malahan dibesarkan skop kepada open skill. Satu penjelasan mengapa sesetengah kajian mendapati keputusan yang berbeza adalah kerana faktor perbezaan individu yang mempengaruhi pembelajaran, prestasi dan kognitif (Vealey \& Greenleaf, 2006). Penyelidik tidak dapat mengawal keupayaan imageri, kawalan dan pengalaman yang lepas yang ada pada atlet. Keupayaan imageri mempunyai dua faktor yang berpengaruh iaitu bagaimana kejelasan atlet boleh melihat imej dan bagaimana terperinci nya.

\section{Kesimpulan}

Imageri merupakan satu teknik latihan psikologi yang digunakan bagi membantu dalam meningkatkan prestasi sukan di samping dapat memberikan kesan yang optimum kepada keseluruhan pasukan. Walaupun dapatan kajian ini menunjukkan tidak terdapat perbezaan yang 
signifikan dari segi pencapaian namun pencapaian min pasukan adalah meningkat. Berkemungkinan latihan imageri ini perlu dipanjangkan tempoh latihannya dan berkemungkinan juga ia perlu dikombinasikan dengan lain-lain aspek psikologi bagi memberikan kesan yang positif terhadap pencapaian. Aspek imageri bukan sahaja boleh dikaji dari aspek kemahiran close loop tapi ia boleh juga diuji pada kemahiran open loop.

\section{RUJUKAN}

Afrouzeh, M., Sohrabi, M., Torbati, H. R. T., Gorgin, F., \& Mallett. L. (2013). Effect of PETTLEP imagery training on learning of new skills in novice volleyball players. Life Science Journal, 10 (1), 231-238.

Barrit, J. (2008). Place kicking in rugby-the continuum and beyond. Rugby Football Union.

Bell, R. J., \& Thompson, C. L. (2007). Solution-focused guided imagery for a golfer experiencing the yips: A case study. The Online Journal of Sport Psychology, 9(1), 1-11.

Burton, D., \& Raedeke, T. (2008). Sport Psychology for Coaches. 1st. Edition, Human Kinetics, USA.

Callow, N., Roberts, R., \& Fawkes, J. (2006). Effects of dynamic and static imagery on vividness of imagery skiing performance, and confidence. Journal of Imagery Research in Sport and Physical Activity, 1, 1-15.

Cumming, J., Nordin, S., Horton, R., \& Reynolds, S. (2006). Examining the direction of imagery and self-talk on dart-throwing performance and self-efficacy. The Sport Psychologist, 20, 257-274.

Evans, L., Jones, L., \& Mullen, R. (2004). An imagery intervention during the competitive season with an elite rugby union player. The Sport Psychologist, 18, 252-271.

Gould, D., Damarjian, N., \& Greenleaf, C. (2002). Imagery training and sel-efficacy. In J. Van Ralte and B. Brewer (Eds.), Exploring sport and exercise psychology (2nd ed.; pp. 49-74). Washington, DC: American Psychological Association.

Gurupreet S., Nishan S. D., \& Pankaj S. (2014). Effect of Imagery Intervention on Performance of the Soccer Players. International Journal of Behavioral Social and Movement Sciences, vol.03, 23 40.

Hall, C. R. (2001). Imagery in sport and exercise. In R. N. Singer, H. A. Hausenblas, \& C. M. Janelle (Eds.), The handbook of sport psychology (2nd ed., pp. 529-549). New York: John Wiley \& Sons Inc. Hall.

IRB (2013). Laws of the Game: Rugby Union International Rugby Board: Dublin, Ireland.

Jordet, G. (2005). Perceptual Training in Soccer: An Imagery Intervention Study with Elite Players. Journal of Applied Sport Psychology, 17:2, 140-156.

Kossert, A. L., \& Munroe-Chandler, K. (2007). Exercise imagery: A systematic review of the empirical literature. Journal of Imagery Research in Sport and Physical Activity, 2, 1-32.

Lang, P. J. (1977). "Imagery in therapy: An Information-processing analysis of fear", Behavior Therapy, vol. 8, pp. 862-886.

Lang, P. J. (1979). A bio-informational theory of emotional imagery. Psychophysiology, 17, 495-512.

Malouff, J., McGee, J., Halford, H., \& Rooke, S. (2008). Imagery and the self-efficacy in baseball games. Journal of Sport Behavior, 31(3), 264-275.

Mamassis, G., \& Doganis, G. (2004). Effects of a mental training program on juniors precompetitive anxiety, self-confidence, and tennis performance. Journal of Applied Sport Psychology, 16, 118137.

Martin, K. A., Moritz, S. E., \& Hall, C. (1999). Imagery use in sport: A literature review and applied model. The Sport Psychologist, 13, 245-268.

Morris, T., Spittle, M., \& Watt, A. P. (2005). Imagery in sport. Champaign: Human Kinetics. 
Mouratidis, A., Vansteenkiste, M., Lens, W., \& Sideridis, G. (2008). The motivating role of positive feedback in sport and physical education: Evidence for a motivational model. JSEP, 30: 240-268.

Nasr Chalghaf, Souhir Sbaa, Marc Leveque, \& Fairouz Azaiez. (2013). Judo's Mental Imagery Training and Technical Acquisitions among High Institute Students. Journal of Research \& Method in Education, 2, 62-68.

Pavely, S., Adam, D. R., Francesco, T. D., Larkham, S. Maher, C. (2009). Execution and differences between passes to the left and right made by first grade rugby union players. Physical Therapy in Sport. 10, 136-141.

Post, P., Muncie, S., \& Simpson, D. (2012). The effect of imagery training on swimming performance: An applied investigation. Journal of Applied Sport Psychology, 24, 323-337.

Post, P., Wrisberg, C. A., \& Mullins, S. (2010). A field test of the influence of pre-game imagery on basketball free throw shooting. Journal of Imagery Research in Sport \& Physical Activity, 5(1), 1932-0191.

Reiser, M., Büsch, D., \& Munzert, J. (2011). Strength gains by motor imagery with different ratios of physical to mental practice. Front. Psychology 2:194.

Roberts, R., Callow, N., Hardy, L., Markland, D., \& Bringer, J. (2008). Movement imagery ability: Development and assessment of a revised version of the vividness of movement imagery questionnaire. Journal of Sport \& Exercise Psychology, 30, 200221.

Robin, N., Dominique, L., Toussaint, L., Blandin, Y., Guillot, A., \& Le Her. M., (2007). Effects of motor imagery training on service return accuracy in tennis: the role of imagery ability. International Journal of Sport and Exercise Psychology, 5(2), 175-188.

Rodlo, S. J. (2007). Effect of biofeedback and imagery on learning in a competitive environment. Journal of Sport \& Exercise Psychology, Suppl. 29, S118.

Short, S., Bruggeman, J., Engel, S., Marback, T., Wang, L., Willadsen, A., \& Short, M. (2002). The effect of imagery function and imagery direction on self-efficacy and performance on a golfputting task. The Sport Psychologist, 16, 48-67.

Short, S. E., Ross-Stewart, L., \& Monsma, E. V. (2006). "Onwards with the evolution of imagery research in sport psychology", Athletic Insight, vol. 8, no. 3.

Smith, D., Wright, C., Allsopp, A., \& Westhead, H. (2007). It's all in the mind: PETTLEP-based imagery and sports performance. Journal of Applied Sport Psychology, 19, 80-92.

Vealey, R.S. \& Greenleaf, C. (2006). Seeing is believing: Understanding and using imagery in sport. In J. M. Williams (Ed.), Applied sport psychology: Personal growth to peak performance (5th ed., pp. 285-305). Mountain View, CA: Mayfield Publishing.

Wade, W., Munroe-Chandler, K. J., \& Hall, C. R. (2007). Imagery intervention with youth swimmers. Journal of Sport \& Exercise Psychology, Suppl.29, S215.

Watt, A. P., \& Morris, T. (1998). The Sport Imagery Ability Measure: Development and reliability analysis. Paper presented at the 33rd Australian Psychological Society Conference (October), Melbourne, Australia.

William, S. E., Cooley, S.J., Newell, E., Weibull, E., \& Cumming, J. (2013). Seeing the Difference: Developing Effective Imagery Scripts for Athletes. Journal of Sport Psychology in Action. 4:2, 109-121.

Williams, S. E., \& Cumming, J. (2011). Measuring athlete imagery ability: The sport imagery ability questionnaire. Journal of Sport \& Exercise Physiology, 33, 416-440.

Đ- Mohd Huzairi Mohd Sani

Kementerian Pendidikan Malaysia

Malaysia 